OPEN ACCESS

Edited and reviewed by:

Jerwen Jou,

The University of Texas Rio Grande

Valley, United States

*Correspondence: Michaela Rohr

m.rohr@mx.uni-saarland.de

Specialty section:

This article was submitted to

Cognitive Neuroscience,

a section of the journal

Frontiers in Human Neuroscience

Received: 01 August 2021

Accepted: 05 August 2021

Published: 01 September 2021

Citation:

Rohr M and Wentura D (2021) Corrigendum: Degree and Complexity

of Non-conscious Emotional Information Processing - A Review of Masked Priming Studies.

Front. Hum. Neurosci. 15:751707. doi: 10.3389/fnhum.2021.751707

\section{Corrigendum: Degree and Complexity of Non-conscious Emotional Information Processing - A Review of Masked Priming Studies}

\author{
Michaela Rohr* and Dirk Wentura \\ Department of Cognitive Psychology, Saarland University, Saarbrücken, Germany
}

Keywords: (non-)consciousness, emotion, affect, masked priming, evaluative priming

\section{A Corrigendum on}

Degree and Complexity of Non-conscious Emotional Information Processing - A Review of Masked Priming Studies

by Rohr, M., and Wentura, D. (2021). Front. Hum. Neurosci. 15:689369. doi: 10.3389/fnhum.2021.689369

In the original article, there was an error. We wrongly stated that participants in the study of Gibbons (2009) were partly aware of the prime stimuli. This was incorrect. In this study, objective unawareness was given.

A correction has been made to the section: Is it 'cold' cognitive processing or are 'hot' emotion-related processes involved?, Paragraph 4 . The corrected paragraph is below:

Of note, in some of these studies, participants were partly aware of the prime stimuli (e.g., Li et al., 2008). Obtaining misattribution effects under conditions of objective unawareness seems thus more difficult (but see Gibbons, 2009; Rohr et al., 2015; for exceptions). Moreover, moderation of evaluative priming or misattribution effects in clinical populations might also stem from cognitive biases in these populations and not from processes related to 'hot' affect.

The authors apologize for this error and state that this does not change the scientific conclusions of the article in any way. The original article has been updated. 


\section{REFERENCES}

Gibbons, H. (2009). Evaluative priming from subliminal emotional words: insights from event-related potentials and individual differences related to anxiety. Conscious. Cogn. Int. J. 18, 383-400. doi: 10.1016/j.concog.2009.02.007

Li, W., Zinbarg, R. E., Boehm, S. G., and Paller, K. A. (2008). Neural and behavioral evidence for affective priming from unconsciously perceived emotional facial expressions and the influence of trait anxiety. J. Cogn. Neurosci. 20, 95-107. doi: 10.1162/jocn.2008.20006

Rohr, M., Degner, J., and Wentura, D. (2015). The "emotion misattribution" procedure: processing beyond good and bad under masked and unmasked presentation conditions. Cogn. Emot. 29, 196-219. doi: 10.1080/02699931.2014.898613
Publisher's Note: All claims expressed in this article are solely those of the authors and do not necessarily represent those of their affiliated organizations, or those of the publisher, the editors and the reviewers. Any product that may be evaluated in this article, or claim that may be made by its manufacturer, is not guaranteed or endorsed by the publisher.

Copyright (c) 2021 Rohr and Wentura. This is an open-access article distributed under the terms of the Creative Commons Attribution License (CC BY). The use, distribution or reproduction in other forums is permitted, provided the original author(s) and the copyright owner(s) are credited and that the original publication in this journal is cited, in accordance with accepted academic practice. No use, distribution or reproduction is permitted which does not comply with these terms. 